\title{
$17-\beta$-Estradiol Enhanced Allodynia of Inflammatory Temporomandibular Joint through Upregulation of Hippocampal TRPV1 in Ovariectomized Rats
}

\author{
Yu-Wei Wu (冊育伟), ${ }^{1}$ Ye-Ping Bi (毕野平), ${ }^{2}$ Xiao-Xing Kou (寇晓星), ${ }^{1}$ Wen Xu (许文), ${ }^{2}$ Li-Qun Ma (马丽群), ${ }^{3}$ \\ Ke-Wei Wang (王克威), ${ }^{2}$ Ye-Hua Gan (甘业华), ${ }^{1}$ and Xu-Chen Ma (马绪臣) ${ }^{1}$ \\ ${ }^{1}$ Center for Temporomandibular Disorders and Orofacial Pain, Peking University School and Hospital of Stomatology, Beijing 100081, People's Republic of \\ China, ${ }^{2}$ Neuroscience Research Institute and Department of Neurobiology, Key Laboratory for Neuroscience of Ministry of Education and Health, Peking \\ University, Beijing 100191, People's Republic of China, and 'Department of Hypertension and Endocrinology, Daping Hospital, Third Military Medical \\ University, Chongqing 400042, People's Republic of China
}

Temporomandibular disorders (TMDs) predominantly affect reproductive female patients, with pain the most frequent complaint. Although estrogens are believed to play important roles in TMD pain, the mechanism underlying modulation of TMD pain by estrogens remains largely unknown. Accumulating evidence implies that the hippocampus is involved in sexual dimorphism of pain sensitivity. In this study, we investigated the hippocampal TRPV1 (transient receptor potential vanilloid 1) expression in ovariectomized rats that received $17-\beta$-estradiol substitution and found that $17-\beta$-estradiol enhanced the mechanical allodynia of inflamed temporomandibular joint (TMJ) induced by complete Freund's adjuvant. Real-time PCR and immunoblotting demonstrated that TMJ inflammation significantly induced hippocampal TRPV1 expression compared with the control group but failed to induce it in the ovariectomized rats that received no estradiol replacement. In addition, estradiol potentiated TMJ inflammation-induced hippocampal TRPV1 expression in a dose-dependent manner in the ovariectomized rats. In contrast, TRPV1 transcription in amygdala, prefrontal cortex, and thalamus was not affected by TMJ inflammation and estradiol. Immunostaining showed TRPV1 localized in the processes and cytoplasm of pyramidal neurons in CA1-CA3 regions of the hippocampus. Moreover, intrahippocampal injection of TRPV1 antagonists capsazepine and 5 '-iodoresiniferatoxin into the CA1 region of the hippocampus significantly attenuated allodynia of inflamed TMJ in both nonovariectomized and ovariectomized rats that received estradiol replacement. Our results suggested that hippocampal TRPV1 can modulate central pain processing and estradiol may contribute to the sexual dimorphism of TMD pain sensitivity through upregulation of TRPV1 expression in the hippocampus.

\section{Introduction}

Temporomandibular disorders (TMDs) are an assorted set of clinical conditions characterized by pain in the temporomandibular joint (TMJ) and/or the masticatory muscles. TMD has the highest prevalence in women aged $20-40$ years, approximately twice that in men, typically with onset of pain after puberty and peaking in the reproductive years (Warren and Fried, 2001). TMD pain is significantly related to synovitis, internal derangement, and osteoarthritis, indicating that joint inflammation could be a major reason for TMD pain (Holmlund et al., 1989; Murakami et al.,

\footnotetext{
Received Dec. 21, 2009; accepted Jan. 25, 2010.

This project was supported by National Natural Science Foundation of China Grants 30740046 to Y.-H.G. and 30970919 to K.-W.W. We thank Dr. Kai-Yuan Fu for technical assistance with the electronic von Frey anesthesiometer and Deng-Cheng Wu for immunohistochemistry. We are also grateful to Dr. Zhi-Ming Zhu at Daping Hospital (Third Military Medical University, Chongqing 400042, People's Republic of China) for the generous gift of TRPV1 knock-out mice.

Correspondence should be addressed to either Ye-Hua Gan (甘业华) or Xu-Chen Ma (马绪臣)，Center for Temporomandibular and Orofacial Pain, Peking University School and Hospital of Stomatology, 22 Zhongguancun Nandajie, Haidian District, Beijing 100081, People's Republic of China. E-mail: kqyehuagan@bjmu.edu.cn or kqxcma@bjmu.edu.cn.

DOI:10.1523/JNEUROSC1.6323-09.2010

Copyright $\odot 2010$ the authors $\quad 0270-6474 / 10 / 308710-10 \$ 15.00 / 0$
}

1991; Israel et al., 1997; Kopp, 1998). Although sex-based differences in TMD pain perception may also be related to social and cultural factors, attention has long been paid to the possible roles that estrogens play in TMD (Abubaker et al., 1993; Okuda et al., 1996; LeResche et al., 1997, 2003; Cheng et al., 2000; Landi et al., 2004).

Accumulating evidence suggests that the hippocampus is involved in sex-based differences in pain perception. For instance, injection of formalin into the hindpaw can induce higher hippocampal choline acetyltransferase activity and higher expression of hippocampal c-fos (a marker for neural activation) in female rats than in male rats (Aloisi et al., 1996, 1997). Recent observation showed that the human hippocampus also displays sexual dimorphism in pain processing (Henderson et al., 2008). Based on these results, we hypothesized that estrogen might affect the expressions or functions of pain-related genes in the hippocampus after TMJ inflammation.

Transient receptor potential vanilloid 1 (TRPV1) is a nonselective cation channel, originally identified as the capsaicin receptor (Caterina et al., 1997). It is mainly expressed in the peripheral nervous system and plays a key role in detection of noxious stimuli, such as capsaicin, acid, heat, and endogenous ligands (Szallasi 
et al., 2007). TRPV1 has also been shown to be expressed in the hippocampus (Toth et al., 2005; Cristino et al., 2006). Hippocampal TRPV1 can directly mediate synaptic plasticity and is involved in anxiety-related behaviors and conditioned fear (Marsch et al., 2007; Alter and Gereau, 2008; Gibson et al., 2008; Li et al., 2008), implying that hippocampal TRPV1 could be related to the affective or cognitive aspects of pain. Interestingly, estrogen was shown not only to regulate hippocampal synaptic plasticity (Ishii et al., 2007; Liu et al., 2008), but also to alter the processing of nociceptive sensory information and analgesic responses in the CNS (Ryan and Maier, 1988; Cicero et al., 1996; Loyd et al., 2008). In addition, estrogen can also increase TRPV1 expression in dorsal root ganglion neurons of primary pain pathways (Tong et al., 2006). The question then arises as to whether estrogen can affect the TRPV1 expression in the hippocampus and therefore contribute to pain sensitivity of TMJ inflammation. To address this question, investigations at molecular and behavioral levels were performed in the present study to examine whether TMJ inflammation and $17-\beta$-estradiol could affect the expression of TRPV1 in the hippocampus and whether $17-\beta$-estradiol could alter the mechanical allodynia of inflamed TMJ.

\section{Materials and Methods}

Animals. The experimental protocols were approved by the Animal Use and Care Committee of Peking University (Beijing, People's Republic of China) and were consistent with the Ethical Guidelines of the International Association for the Study of Pain. Adult female Sprague Dawley rats $(180-200 \mathrm{~g})$ were housed under controlled temperature $\left(22 \pm 1^{\circ} \mathrm{C}\right)$ on a $12 \mathrm{~h}$ light/dark cycle and had ad libitum access to food and water. The rats were randomly divided into six groups with at least six rats for each group, including the control group, sham-ovariectomized group, and ovariectomized groups that received $17-\beta$-estradiol replacement at doses of $0,20,80$, and $200 \mu \mathrm{g}$, respectively. Another six groups, designed the same as the above, were used to examine whether the hippocampal TRPV1 expression could be affected by estradiol in the ovariectomized rats without TMJ inflammation.

Estradiol administration. After being intraperitoneally anesthetized with sodium pentobarbital ( $50 \mathrm{mg} / \mathrm{kg}$ body weight), the rats were bilaterally ovariectomized or operated on with sham ovariectomies and allowed to recover for 1 week. The ovariectomized rats were dosed with $17-\beta$-estradiol dissolved in corn oil by subcutaneous injection daily in the morning at doses of $0,20,80$, and $200 \mu \mathrm{g}$ per rat, respectively, in a volume of $200 \mu \mathrm{l}$ for $12 \mathrm{~d}$. To confirm the effectiveness of estradiol replacement, the body weights of the rats were measured after completion of estradiol replacement. The control, sham-ovariectomized, and ovariectomized rats that received no estradiol replacement were subcutaneously injected with the same amount of corn oil.

Induction of TMJ inflammation. On the 12th day of estradiol replacement, the sham-ovariectomized and ovariectomized rats were anesthetized and injected with $50 \mu \mathrm{l}$ of complete Freund's adjuvant (CFA) (Sigma) (oil/saline at ratio of 1:1) into the bilateral TMJs to induce TMJ inflammation as described in a previous study (Ren, 1999). For the control rats, $50 \mu \mathrm{l}$ of saline was injected into the bilateral TMJs. TMJ inflammation was examined by physical examination and histopathology.

Measurement of head withdrawal threshold. The head withdrawal threshold was measured as reported previously (Ren, 1999). Briefly, $20 \mathrm{~h}$ after injection of CFA into TMJ, the rats were habituated to stand on their hindpaws and lean against the experimenter's hand wearing a regular leather working glove. The rats were unrestrained but remained motionless during the test session. The filament with progressive, increasing forces from the electronic von Frey anesthesiometer (IITC Life Science) was applied to the TMJ region until the head was withdrawn and the applied force was recorded. The head withdrawal threshold was calculated as mean \pm SEM based on at least five measurements per joint and six rats per group.

Measurement of food intake. Food intake is negatively associated with TMJ inflammation/pain and can be used as an indicator for TMJ inflam-
A
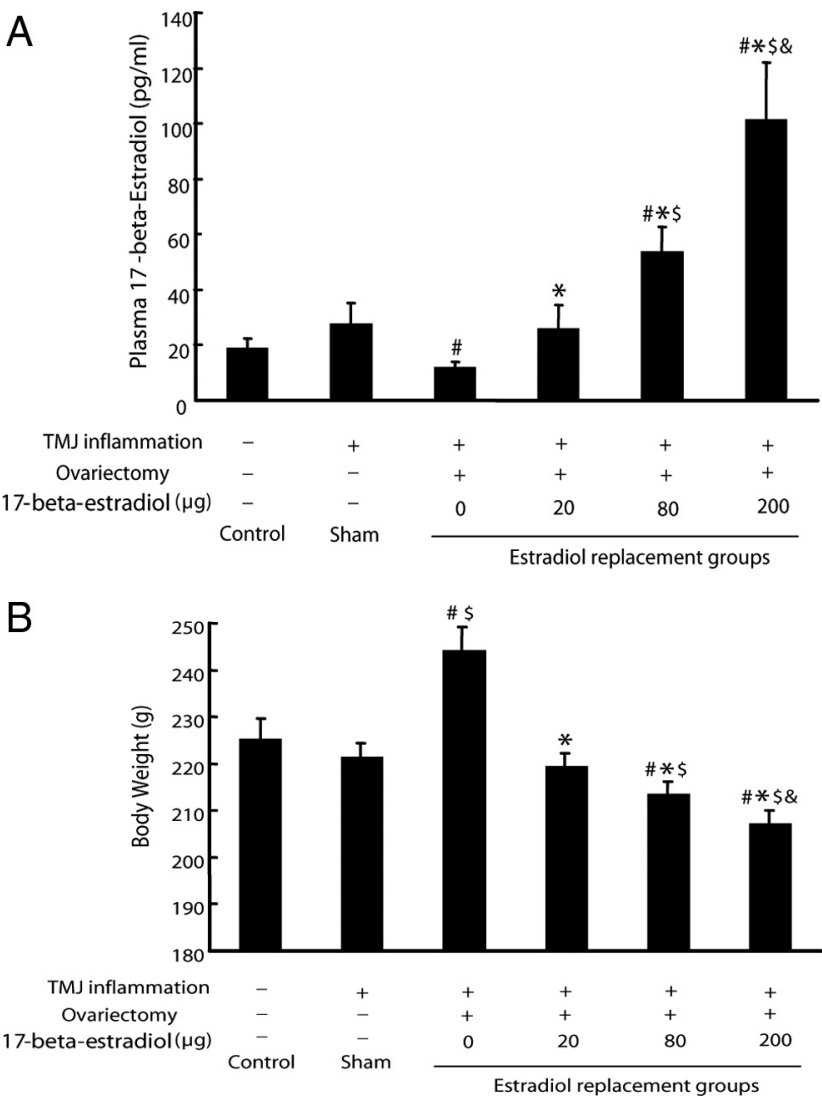

Figure 1. Confirmation of the effectiveness of ovariectomy and estradiol replacement in rats. $\boldsymbol{A}$, Plasma levels of 17- $\beta$-estradiol. The plasma level of estradiol of the ovariectomized group that received no estradiol replacement was the lowest, and that of the ovariectomized groups that received increasing doses of estradiol increased in dose-dependent manner. Note: The plasma level of estradiol of the $20 \mu \mathrm{g}$ group was similar to that of the control and shamovariectomized groups. ${ }^{\#} p<0.05$ versus control group; ${ }^{*} p<0.05$ versus $0 \mu$ g group; ${ }^{\$} p<$ 0.05 versus $20 \mu$ group; ${ }^{\&} p<0.05$ versus $80 \mu$ group ( $n=6$, two-way ANOVA). $B$, The body weight of the ovariectomized group that received no estradiol replacement was the heaviest, and that of the groups that received increasing doses of estradiol dose-dependently decreased. ${ }^{\#} p<0.05$ versus control group; ${ }^{*} p<0.05$ versus $0 \mu \mathrm{g}$ group; ${ }^{5} p<0.05$ versus $20 \mu \mathrm{g}$ group, ${ }^{\&} p<0.05$ versus $80 \mu$ group $(n=6$, two-way ANOVA).

mation/pain (Harper et al., 2000; Kerins et al., 2003). We measured the food intake with minor modifications in that the rats were initially fasted over a period of time and then the amount of food eaten by rats was measured for a limited time. Briefly, after injection of CFA into TMJ, each rat was kept in one cage supplied without food but with water for $15 \mathrm{~h}$. The rat was then fed with food but without water and the amount of food eaten by the rat during a $2 \mathrm{~h}$ period was recorded as food intake.

Hormonal determination and tissue preparations. The rats were killed with an overdose of sodium pentobarbital (100 mg/kg body weight) $24 \mathrm{~h}$ after induction of TMJ inflammation, and blood was collected from the inferior vena cava. The plasma levels of $17-\beta$-estradiol were determined by radioimmunoassay using a Beckman Coulter Access immunoassay system. The hippocampus was wholly dissected for RNA and protein extraction. The amygdala, prefrontal cortex, and thalamus were dissected for RNA extraction. The TMJ was removed and fixed in $4 \%$ paraformaldehyde in PBS and demineralized in 15\% EDTA. The specimens were dehydrated in graded alcohols and xylene, embedded in paraffin, and cut serially into $5 \mu \mathrm{m}$ sagittal sections. The sections were stained with hematoxylin-eosin.

Quantitative real-time PCR. Total RNA was extracted with TRIzol (Invitrogen) in accordance with the manufacturer's instructions, and the integrity was evaluated by electrophoresis in 1\% agarose gel. Reverse transcription PCR was conducted with an iScript cDNA synthesis kit (Bio-Rad) in $20 \mu \mathrm{l}$ reaction volume containing $1 \mu \mathrm{g}$ of total RNA incubated at $25^{\circ} \mathrm{C}$ for 
$5 \mathrm{~min}$, transcripted at $42^{\circ} \mathrm{C}$ for $30 \mathrm{~min}$, and terminated by heating at $85^{\circ} \mathrm{C}$ for $5 \mathrm{~min}$. The synthesized cDNA was stored at $-20^{\circ} \mathrm{C}$ until use.

Real-time PCR was performed with Power SYBR Green PCR Master Mix (Applied Biosystems) using a 7500 real-time PCR System (Applied Biosystems). The reactions were run in duplicate with $1 \mu \mathrm{l}$ of cDNA template in a $20 \mu \mathrm{l}$ reaction volume with the program running at $50^{\circ} \mathrm{C}$ for $2 \mathrm{~min}$ and $95^{\circ} \mathrm{C}$ for $10 \mathrm{~min}$, followed by 40 cycles of $94^{\circ} \mathrm{C}$ for $15 \mathrm{~s}$ and $60^{\circ} \mathrm{C}$ for $1 \mathrm{~min}$. The amplification specificity was confirmed by melting curve. The mRNA level of the target gene was acquired from the value of threshold cycle $(\mathrm{Ct})$ as a relative level to that of $\beta$-actin through the formula $2^{-\Delta \mathrm{Ct}}(\Delta \mathrm{Ct}=\beta$-actin $\mathrm{Ct}-$ gene of interest $\mathrm{Ct}$ ). The efficiency of the primers was confirmed by sequencing the conventional PCR products before applying for real-time PCR. The primers synthesized according to the sequences in previous reports were as follows: rat TRPV1 sense/antisense, 5'-GACATGCCACCCAGCAGG-3'/5' -TCAATTCCCACACACCTCCC-3' (Mezey et al., 2000); rat $\beta$-actin sense/antisense, 5'-TGACAGGATGCAGAAGGAGA-3'/5' -TAGAGCCACCAATCCACACA-3' (Tian et al., 2007).

Immunohistochemistry. Whole brains were removed from the TRPV1 knock-out mice and wild-type mice (generous gift from Dr. Zhi-Ming Zhu, Daping Hospital, Third Military Medical University, Chongqing, China) and from the female rats at proestrous stage without or with induction of TMJ inflammation for $20 \mathrm{~h}$, and fixed in $4 \%$ paraformaldehyde in PBS. The brains were placed in a $30 \%$ sucrose solution (in $0.1 \mathrm{M}$ PBS) overnight at $4^{\circ} \mathrm{C}$, frozen to $-20^{\circ} \mathrm{C}$, and sectioned $14 \mu \mathrm{m}$ thick on a cryostat. The sections were mounted on poly-L-lysine-coated slides and incubated at room temperature for $10 \mathrm{~min}$ in $3 \% \mathrm{H}_{2} \mathrm{O}_{2}$ to inactivate endogenous peroxidase activity, washed with $0.1 \mathrm{~m}$ PBS, and incubated with anti-TRPV1 (SC-12498, P-19; lot L1302; Santa Cruz Biotechnology) diluted 1:100 in PBS for $1 \mathrm{~d}$ at $4{ }^{\circ} \mathrm{C}$. The sections were thoroughly washed with $0.1 \mathrm{M}$ PBS, followed by incubation with horseradish peroxidaseconjugated secondary antibodies for half an hour at room temperature. After thorough washes with $0.1 \mathrm{M}$ PBS, the sections were visualized using 3,3'-diaminobenzidine (Zhongshan Golden Bridge Biological Technology) for $1 \mathrm{~min}$.

Western blot analysis. The whole hippocampus was homogenized by homogenizer (Ultra-Turrax T10; IKA Laboratory Technology) in an icecold denaturing lysis buffer ( $50 \mathrm{~mm}$ Tris- $\mathrm{HCl}, \mathrm{pH} 7.5,150 \mathrm{~mm} \mathrm{NaCl}, 5$ mM EDTA, 1\% Triton X-100, 1 mm DTT, 1 mm phenylmethylsulfonyl fluoride, $1 \mu \mathrm{g} / \mathrm{ml}$ aprotinin, $1 \mu \mathrm{g} / \mathrm{ml}$ leupeptin) and centrifuged at $13,000 \times g$ for $20 \mathrm{~min}$ at $4^{\circ} \mathrm{C}$. The supernatant was collected and protein concentrations were determined using the BCA assay (Pierce). Protein samples were subjected to $8 \%$ SDS-PAGE and transferred to polyvinylidene difluoride membrane. The membrane was blocked in $5 \%$ nonfat dry milk in TBS-T buffer (50 mm Tris- $\mathrm{HCl}, \mathrm{pH}$ 7.5, $150 \mathrm{~mm} \mathrm{NaCl}, 0.05 \%$ Tween 20) for $1 \mathrm{~h}$ at room temperature and probed with primary antibodies at a dilution of 1:200 for TRPV1 antibody overnight at $4^{\circ} \mathrm{C}$. The membrane was washed extensively with TBS-T and then incubated with horseradish peroxidase-conjugated secondary antibodies for $1 \mathrm{~h}$ at room temperature. After extensive washing with TBS-T, the membrane was visualized using the ECL kit (Applygen Technologies). For internal control, the blots were stripped and reprobed with anti- $\beta$-actin polyclonal antibodies (Santa Cruz Biotechnology) at a dilution of 1:1000.

Intrahippocampal injection of TRPV1 antagonists into CA1 region of hippocampus. TRPV1 antagonists capsazepine (Sigma) and 5'-iodoresiniferatoxin (LC Laboratories) were both dissolved in dimethylsulfoxide (DMSO). The applied doses of capsazepine (10 and $30 \mathrm{nmol}$ in $1 \mu \mathrm{l}$ ) and $5^{\prime}$-iodo-resiniferatoxin $(0.1$ and $0.5 \mathrm{nmol}$ in $1 \mu \mathrm{l})$ were based on previous studies (McGaraughty et al., 2003; Starowicz et al., 2007; Terzian et al., 2009). The solutions were prepared immediately before use.
A

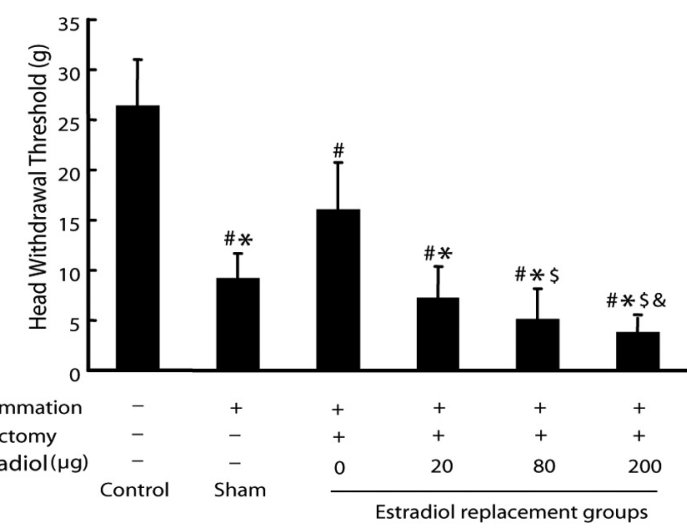

B

B

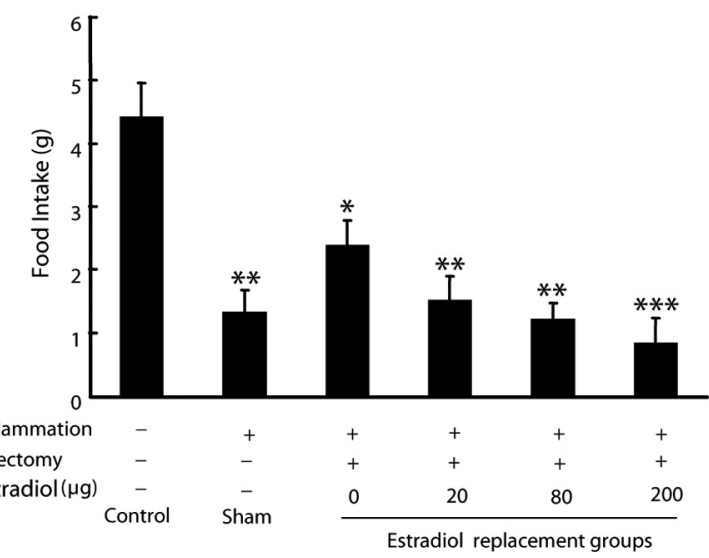

Figure 3. Estradiol exacerbated mechanical allodynia of inflamed TMJ in rats. $A$, Head withdrawal threshold. After induction of TMJ inflammation, the head withdrawal threshold was significantly decreased in the sham-ovariectomized rats and also dose-dependently decreased in the ovariectomized groups that received increasing doses of estradiol. ${ }^{\#} p<0.05$ versus control group; ${ }^{*} p<0.05$ versus $0 \mu$ group; ${ }^{5} p<0.05$ versus $20 \mu$ group; ${ }^{\&} p<0.05$ versus $80 \mu$ group $(n=6$, two-way ANOVA). $\boldsymbol{B}$, Food intake after induction of TMJ inflammation. The food intake was decreased in all of the inflamed TMJ groups compared with the control. ${ }^{*} p<0.05$ versus control group; ${ }^{* *} p<0.01$ versus control group; ${ }^{* * *} p<0.001$ versus control group ( $n=6$, two-way ANOVA).

Female rats $(240-260 \mathrm{~g})$ were anesthetized with sodium pentobarbital (50 mg/kg, i.p.). Two guide cannulas (5 mm in length, $0.6 \mathrm{~mm}$ outer diameter, and $0.3 \mathrm{~mm}$ inner diameter) were bilaterally inserted $1 \mathrm{~mm}$ above the CA1 region of the hippocampi according to the following 
parameters: anteroposterior $=-3.5 \mathrm{~mm}$, left to right $= \pm 2.4 \mathrm{~mm}\left(10^{\circ}\right.$ angle), and dorsoventral $=-2 \mathrm{~mm}$ relative to the bregma and skull surface (Paxinos and Watson, 1997). The cannulas were anchored to the skull with stainless steel screws and dental self-curing acrylic resin. A stainless steel stylet was inserted into the cannula to prevent obstruction and infection. The rats were allowed to recover from surgery for at least $7 \mathrm{~d}$. To ensure induction of TMJ inflammation in the proestrous stage, for which the plasma level of estradiol is highest during the rat estrous cycle (Dupon and Kim, 1973; Lerner et al., 1990), the late metoestrous stage was determined for injecting CFA into the TMJ by obtaining a vaginal smear (data not shown) at 4:00 P.M. daily for two consecutive estrous cycles.

Intrahippocampal injections of the TRPV1 antagonists into the bilateral CA1 regions of the hippocampi were performed with a micromanipulator mounted with two $1 \mu \mathrm{l}$ Hamilton microsyringes. Each microsyringe was connected through a PE-10 polyethylene catheter to an injection cannula that was introduced into the guide cannula with its tip extended $1.0 \mathrm{~mm}$ beyond the tip of the guide cannula. The bilateral hippocampi were simultaneously injected with $1 \mu \mathrm{l}$ of the TRPV1 antagonists or vehicle (saline/DMSO at ratio of 1:1) over $1 \mathrm{~min}$, and the injection cannula was kept in place for an additional $1 \mathrm{~min}$ to allow for diffusion.

The effect of intrahippocampal injection of capsazepine ( $30 \mathrm{nmol}, n=$ $6)$ and vehicle $(n=5)$ or $5^{\prime}$-iodo-resiniferatoxin $(0.1 \mathrm{nmol}$ and $0.5 \mathrm{nmol}$, $n=6)$ and vehicle $(n=6)$ into the CA1 region on the baselines of head withdrawal threshold and food intake was initially examined. The head withdrawal threshold was measured for a period of 65 min after hippocampal injection. All of the rats were injected with CFA into TMJs to induce TMJ inflammation, and head withdrawal thresholds were measured $20 \mathrm{~h}$ after CFA injection. The rats were then immediately intrahippocampally injected with capsazepine ( 10 and $30 \mathrm{nmol}, n=4)$ and the vehicle $(n=3)$ or 5 '-iodo-resiniferatoxin $(0.1$ and $0.5 \mathrm{nmol}, n=4)$ and the vehicle $(n=5)$, and head withdrawal thresholds were remeasured for a period of $65 \mathrm{~min}$. During the period of $20 \mathrm{~h}$ for generation of TMJ inflammation, the rats were supplied with water but without food, and food intake was measured after the intrahippocampal injections and the measurement of head withdrawal threshold. The experiments of intrahippocampal injection and behavior testing were conducted on the basis of a double-blind design. The rats were killed for examination of the placement of cannulas. Coronal sections $(30 \mu \mathrm{m})$ of the brains were sliced on a cryostat, and the sections were examined under a microscope.

To assess whether TRPV1 antagonists could also attenuate allodynia of the inflamed TMJ in estradiol-treated rats, head withdrawal threshold and food intake were measured in the ovariectomized rats $(240-260 \mathrm{~g})$ that received $200 \mu \mathrm{g}$ of $17-\beta$-estradiol daily for $12 \mathrm{~d}$. The procedures of pain assessment for both head withdrawal and food intake were the same as described above with intrahippocampal injection with capsazepine (30 $\mathrm{nm}, n=6)$ and vehicle $(n=5)$ or $5^{\prime}$-iodo-resiniferatoxin $(0.5 \mathrm{~nm}, n=5)$ and vehicle $(n=5)$ into the CA1 region.

Statistical analysis. Statistical analysis was performed with SPSS 11.5 for Windows. All data were presented as mean \pm SEM. Differences between groups were examined by two-way ANOVA, whereas difference between two groups was examined using an independent samples $t$ test. A value of $p<0.05$ was considered to be statistically significant.

\section{Results}

Plasma level of estradiol increased and body weight decreased with increasing doses of replaced estradiol

Plasma level of $17-\beta$-estradiol was measured to confirm the effectiveness of ovariectomy and estradiol replacement. While the plasma levels of estradiol in the ovariectomized groups receiving with 0 and $200 \mu \mathrm{g}$ of estradiol were expectedly the lowest $(12.26 \pm 1.69 \mathrm{pg} / \mathrm{ml})$ and highest $(102 \pm 20.5 \mathrm{pg} / \mathrm{ml})$, respectively, among the all groups, the plasma levels of estradiol in the ovariectomized groups receiving the increasing doses of estradiol were increased dose dependently $(p<0.05)$. While the plasma level of estradiol of the $20 \mu \mathrm{g}$ group was similar to that of the control and sham-ovariectomized groups $(p>0.05)$, the plasma levels of estradiol in the 80 and $200 \mu$ g groups were
A
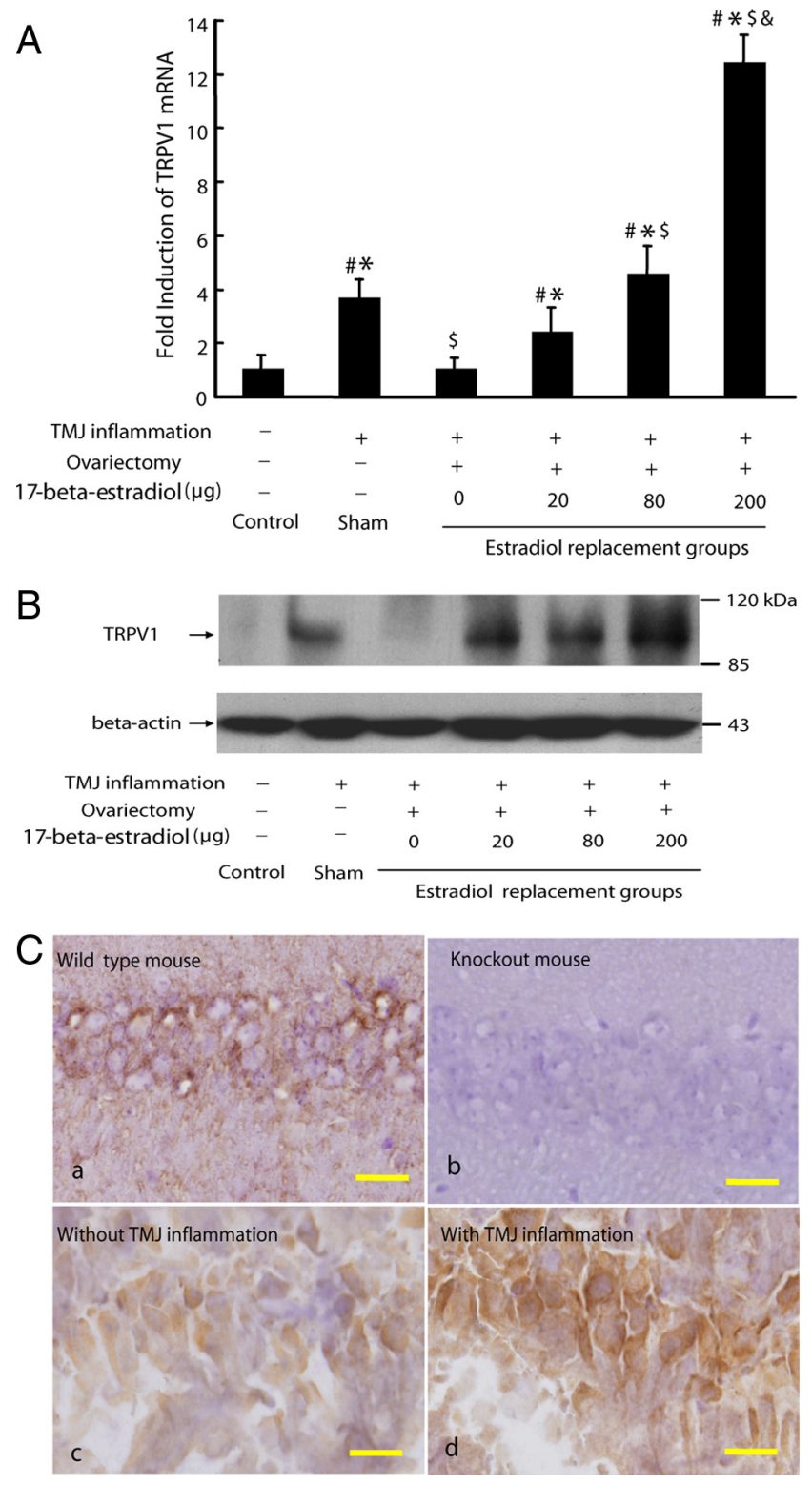

Figure 4. Hippocampal TRPV1 expression upregulated by TMJ inflammation and further potentiated by estradiol. $\boldsymbol{A}$, Real-time PCR analysis for TRPV1 expression in the hippocampus. The hippocampal TRPV1 mRNA was induced by TMJ inflammation and further potentiated by estradiol in ovariectomized rats. Note: TMJ inflammation failed to induce hippocampal TRPV1 mRNA in the ovariectomized rats that received no estradiol replacement. ${ }^{\#} p<0.05$ versus control group; ${ }^{*} p<0.05$ versus $0 \mu$ g group; ${ }^{\$} p<0.05$ versus $20 \mu$ group; ${ }^{\&} p<0.05$ versus $80 \mu \mathrm{g}$ group ( $n=3$, two-way ANOVA). $\boldsymbol{B}$, Representative immunoblotting for TRPV1 expression in the hippocampus of rats. The hippocampal TRPV1 protein expression corresponded to its mRNA expression pattern. $\beta$-Actin was served as an internal control for equal loading. $\boldsymbol{C}$, Representative immunostaining for TRPV1 expression in the hippocampus of rat and mouse. TRPV1like immunostaining was selectively detected in the hippocampus from the wild-type mouse $(\boldsymbol{a})$ but not from the TRPV1 knock-out mouse (b). TRPV1 immunostaining was in the cytoplasma and processes of the pyramidal neurons throughout the CA1-CA3 subfields of the hippocampus in the rat. The intensity of TRPV1 immunostaining was increased in the above areas in the hippocampus of the rat with inflamed TMJ (c), compared with that of the rat without TMJ inflammation (d). Scale bars, $25 \mu \mathrm{m}$.

higher than those of the control and sham-ovariectomized groups $(p<0.05)$.

In contrast, the body weight of the ovariectomized group receiving no estradiol replacement was heaviest, and that of the groups receiving increasing doses of estradiol decreased dose dependently (Fig. $1 \mathrm{~B}$ ), consistent with the previous study showing 
that administration of estradiol could prevent ovariectomized rats from the increase of body weight (Hertrampf et al., 2007). Since the hippocampal TRPV1 mRNA expression was not altered in the six groups without TMJ inflammation (data not shown), all the data shown in this study were only from the six groups with TMJ inflammation.

\section{Verification of CFA-induced \\ TMJ inflammation}

Twenty-four hours after injection of CFA into TMJ, chromodacryorrhea in the eyes and intense redness and swelling over the TMJ region were observed in all the CFAinjected groups, but not in the control group. Histopathologic examination showed that the synovial tissues were hypertrophied, with an increase of synoviocytes and infiltrated leukocytes in the CFA-injected TMJ (Fig. 2B), while there were no such changes in the control TMJ (Fig. 2A). Angiogenesis and fibrin-like exudate in the superior joint space were also observed in the CFA-injected TMJ compared with the control joint (Fig. 2), indicating that injection of CFA into the TMJ successfully induced TMJ inflammation.

Estradiol exacerbated mechanical allodynia of inflamed TMJ To examine whether estradiol could affect TMJ inflammatory pain, mechanical allodynia of inflamed TMJ was evaluated by measuring head withdrawal threshold and then food intake after injection of CFA into the TMJ. The lower the head withdrawal threshold and food intake are, the more severe inflammation/ pain of the TMJ will be. As shown in Figure 3A, head withdrawal threshold was significantly decreased in all the CFA-treated groups compared with the control $(p<0.05)$. Among the CFAtreated groups, the head withdrawal threshold for ovariectomized rats that received no estradiol replacement was higher than that for the sham-ovariectomized group $(p<0.05)$ and for the groups that received estradiol replacement $(p<0.05)$. Moreover, the head withdrawal threshold was dose dependently decreased in the ovariectomized groups that received the increasing doses of estradiol $(p<0.05)$.

Before induction of TMJ inflammation, food intake was not different among all groups (data not shown). However, food intake was decreased in all of the CFA-injected groups compared with the control $(p<0.05)$. Although there was no statistical significance $(p>0.05)$, food intake of the CFA-treated groups showed a trend of declining with the increasing doses of estradiol in the ovariectomized rats (Fig. $3 B$ ).

\section{Hippocampal TRPV1 expression upregulated by TMJ inflammation and further potentiated by estradiol} Since the hippocampal TRPV1 mRNA expression was not altered in the experimental batch in which all of the six groups were without TMJ inflammation, we examined whether TRPV1 expression in the hippocampus could be affected by TMJ inflammation. As shown in Figure $4, A$ and $B$, both mRNA and protein expressions of hippocampal TRPV 1 were upregulated by CFAinduced TMJ inflammation compared with the control group. In contrast, TMJ inflammation failed to induce hippocampal
TRPV1 expression in the ovariectomized rats that received no estradiol replacement. This upregulation of hippocampal TRPV1 by TMJ inflammation was further potentiated by estradiol in a dose-dependent manner in the ovariectomized rats $(p<0.05)$.

Immunohistochemistry showed that TRPV1-like immunostaining was in the cytoplasma and processes of the pyramidal neurons throughout the CA1-CA3 subfields of the hippocampus, and that the intensity of immunostaining was increased in the hippocampus from the rats with inflamed TMJ compared with the rats without inflamed TMJ (Fig. 4C). The TRPV1-like immunostaining was only observed in the hippocampus from the wild-type mice but not from the TRPV $1^{-1-}$ knock-out mice (Fig. $4 C)$, confirming the specificity of the TRPV1 antibody.

\section{Blocking TRPV1 in hippocampus attenuated mechanical allodynia of inflamed TMJ}

To examine whether the induction of TRPV1 expression in the hippocampus by TMJ inflammation and estradiol replacement was specific to the hippocampus, we also investigated the expression of TRPV1 mRNA in the amygdala, prefrontal cortex, and thalamus. TRPV1 transcription was not affected in these areas by TMJ inflammation and estradiol replacement $(p>0.05)$ (Fig. 5), indicating that the expression of TRPV1 mRNA in the amygdala, prefrontal cortex, and thalamus was not affected by TMJ inflammation and estradiol replacement.

To further confirm whether the function of hippocampal TRPV1 was involved in TMJ inflammation pain, we performed intrahippocampal injection of TRPV1 antagonists capsazepine and $5^{\prime}$-iodo-resiniferatoxin into the CA1 region to specifically block TRPV1 function in the neurons of the CA1 region in vivo. As shown in Figure 6, the placements of all the cannulas were confirmed to be within the CA1 region of the hippocampus between bregma $-3.14 \mathrm{~mm}$ and $-4.16 \mathrm{~mm}$ (Paxinos and Watson, 1997). The baseline of head withdrawal threshold was not affected during the period of measurement by intrahippocampal injections of capsazepine $(30 \mathrm{nmol}), 5^{\prime}$-iodo-resiniferatoxin $(0.5$ $\mathrm{nmol}$ ), or vehicle into the CA1 region $(p>0.05)$ (Fig. $7 A, B)$. The head withdrawal threshold was significantly decreased to about 

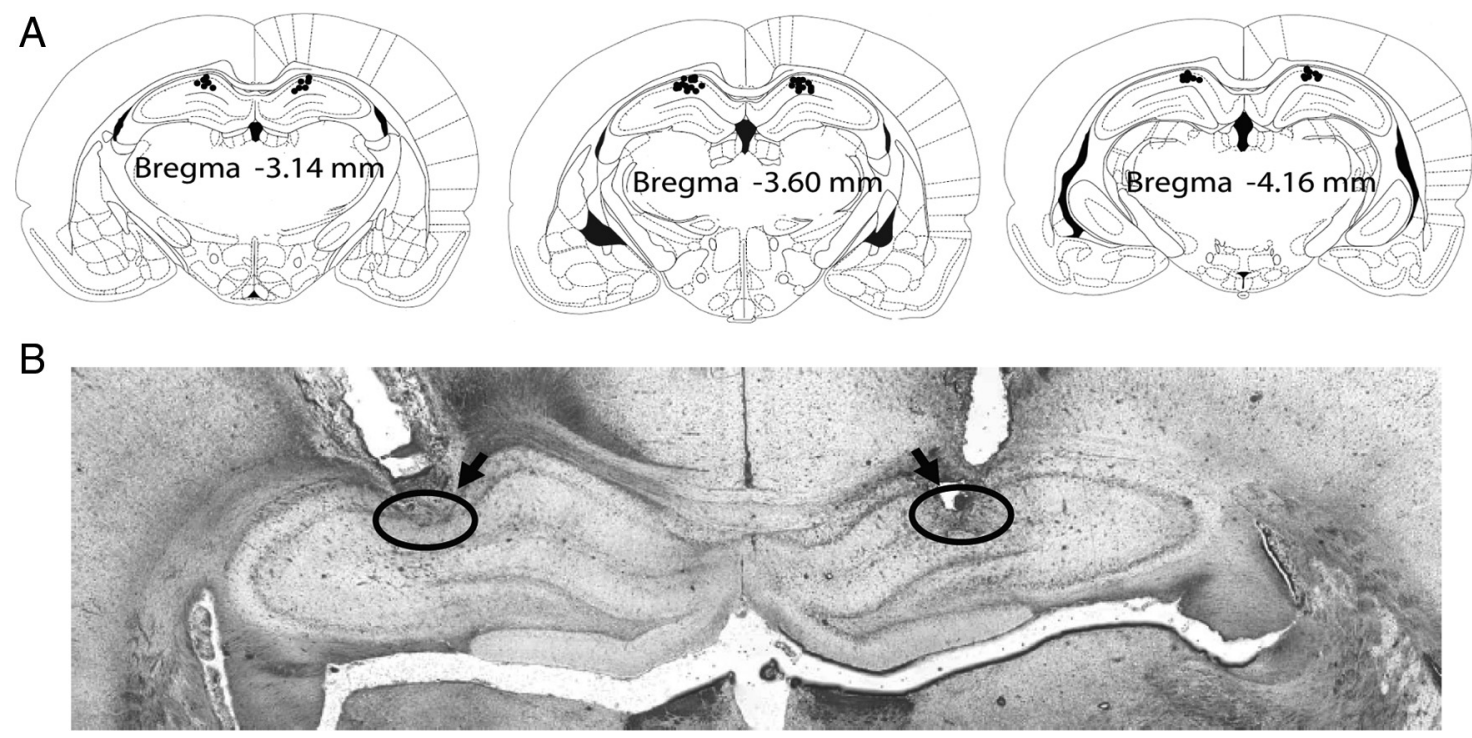

Figure 6. Confirmation of cannula placements in the hippocampus in rats. $A$, Reconstruction of serial coronal sections of the brain illustrates the bilateral injection sites of the cannulas. Black dots on the schematic illustration of the coronal section of rat brain [adapted from the rat brain atlas of Paxinos and Watson (1997)] indicate the placements of cannulas in the brain. $\boldsymbol{B}$, Representative microphotograph of the coronal section shows the placements (indicated by circles and arrows) of a pair of cannulas in the CA1 region of the hippocampus.

one-fifth of the baseline after induction of TMJ inflammation. However, intrahippocampal injections of capsazepine (10 and 30 $\mathrm{nmol})$ and $5^{\prime}$-iodo-resiniferatoxin $(0.1$ and $0.5 \mathrm{nmol})$ reversed the decreased head withdrawal thresholds from 22 to 44 and $63 \%$ of the baseline and from 21 to 42 and $50 \%$ of the baseline, respectively $(p<0.05)($ Fig. $7 A, B)$. While the food intake of the rats with intrahippocampal injections of capsazepine $(30 \mathrm{nmol})$ or 5 '-iodo-resiniferatoxin $(0.5 \mathrm{nmol})$ was not different from that of rats with intrahippocampal injection of vehicle before induction of TMJ inflammation, intrahippocampal injections of capsazepine and $5^{\prime}$-iodo-resiniferatoxin completely blocked the TMJ inflammation-induced decrease of food intake (Fig. 7C,D) $(p<$ $0.05)$. Moreover, intrahippocampal injections of capsazepine $(30 \mathrm{nmol})$ and $5^{\prime}$-iodo-resiniferatoxin $(0.5 \mathrm{nmol})$ in estradioltreated rats also partially and completely reversed the TMJ inflammation-induced decreases of head withdrawal threshold and food intake, respectively (Fig. 8). These results demonstrate that blocking the function of TRPV1 in the hippocampus can attenuate mechanical allodynia of inflamed TMJ.

\section{Discussion}

In the present study, we have shown two important findings regarding hippocampal TRPV1 and female hormone estradiol involved in mechanical allodynia of inflamed TMJ. First, CFAinduced TMJ inflammation upregulated hippocampal TRPV1 expression and estradiol potentiated this upregulation of TRPV1, simultaneously enhancing mechanical allodynia of the inflamed TMJ in the ovariectomized rats. Second, blocking TRPV1 function in the hippocampus by TRPV1 antagonists attenuated mechanical allodynia of inflamed TMJ both in proestrous and the estradiol-treated ovariectomized rats. These results indicated that the hippocampal TRPV1 was involved in central pain processing and that estradiol-exacerbated pain of inflamed TMJ may be through potentiation of the hippocampal TRPV1 expression, a possible molecular mechanism underlying the sexual dimorphism of TMD pain mediated in the CNS.

\section{Modulation of TMJ inflammatory pain by estradiol}

Pronociceptive or antinociceptive effects of estradiol remain fiercely controversial in the literature (Craft, 2007). Although animal studies showed that estradiol can attenuate pain (Gaumond et al., 2005; Kuba et al., 2006; Mannino et al., 2007) or has no effect (Mannino et al., 2005), there are also comparable animal studies that argue that estradiol exacerbates peripheral pain sensitization by decreasing mechanical threshold or increasing response to noxious stimuli administered to the colon and vagina (Bradshaw and Berkley, 2000; Evrard and Balthazart, 2004). Despite the controversy, we showed here that estradiol could exacerbate mechanical allodynia of inflamed TMJ in the ovariectomized rats, suggesting that rats with a higher level of plasma estradiol would be more sensitive to mechanical stimuli over the inflamed TMJ. It has been previously shown that estradiol enhanced visually assessed swelling around the inflamed TMJ (Guan et al., 2005), implying that the TMJ with greater swelling could be more sensitive to mechanical stimuli because of higher pressure in the local tissue than the one with less swelling. Considering that estradiol can modulate the functions of both nervous and immune systems, it is difficult to differentiate whether our observation that estradiol exacerbation of inflamed TMJ pain was caused by estradiol-enhanced inflammation in the TMJ or by estradiol-enhanced sensitization in the nervous system of pain processing, or by both. Given that the estradiol potentiation of the hippocampal TRPV1 expression occurred concomitantly with its exacerbation of allodynia of inflamed TMJ, it is suggested that the hippocampal TRPV1 may play a special role in estradiolmediated inflammatory TMJ pain.

\section{Hippocampal TRPV1 involved in allodynia of inflamed TMJ}

The role of TRPV1 in central pain processing is not well defined. It is suggested that the central TRPV1 may play a key role in broad-spectrum analgesia, since the TRPV1 antagonist with good penetration into the CNS showed stronger analgesic activity than the one with poor penetration (Cui et al., 2006). The hippocampus is associated with memory, stress response, anxiety, and depression (Lathe, 2001) and is generally not recognized as a major area in the brain involved in pain processing. However, studies suggested that the hippocampus may contribute to pain awareness because painful stimuli can induce changes of neuronal activity, blood flow, and c-fos and Egr 1 expressions in the hippocampus (Aloisi et al., 1997; Derbyshire et al., 1997; 


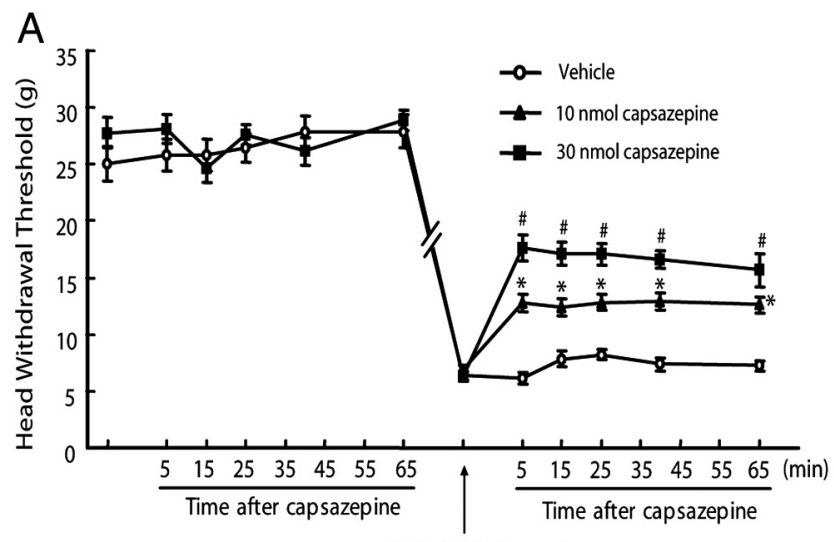

$20 \mathrm{~h}$ after TMJ inflammation

$\mathrm{B}$

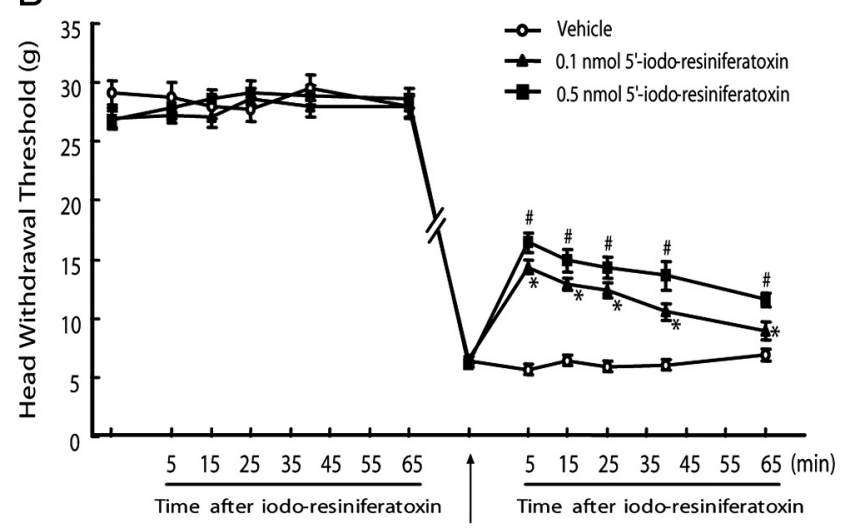

$20 \mathrm{~h}$ after TMJ inflammation

C

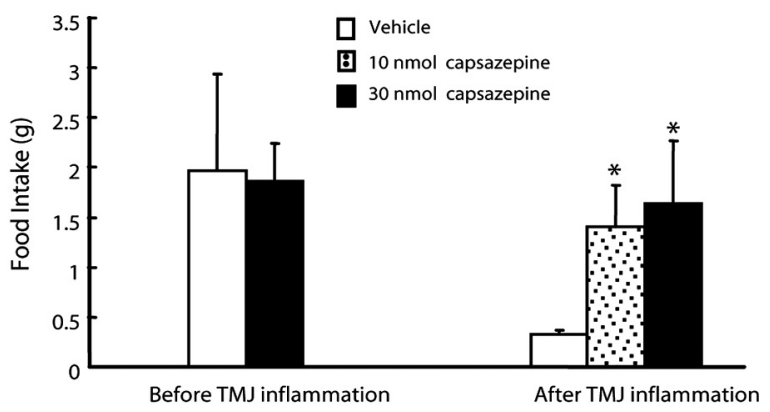

$\mathrm{D}$

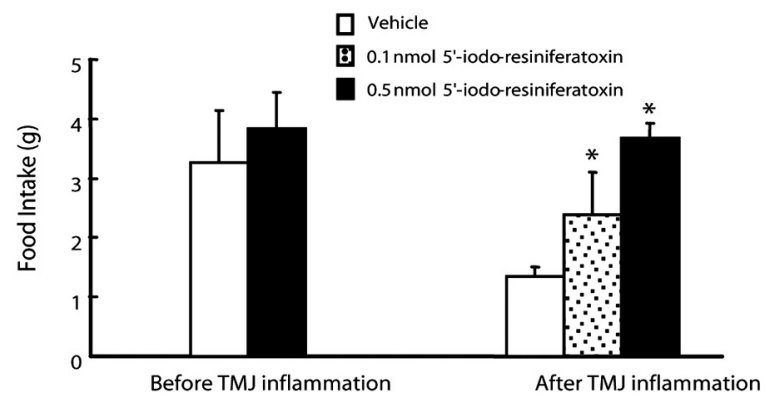

Figure 7. Attenuation of mechanical allodynia of inflamed TMJ by blocking the function of TRPV1 in the hippocampus. $\boldsymbol{A}, \boldsymbol{B}$, Head withdrawal threshold was partially reversed by intrahippocampal injections of TRPV1 antagonists capsazepine $(\boldsymbol{A})$ and $5^{\prime}$-iodo-resiniferatoxin $(\boldsymbol{B})$ into the CA1 region of the hippocampus. The baseline of head withdrawal threshold was not different between intrahippocampal injection of capsazepine $(30 \mathrm{nmol}, n=6)$ and vehicle $(n=5)$ or $5^{\prime}$-iodo-resiniferatoxin $(0.5 \mathrm{nmol}, n=6)$ and vehicle $(n=6)$ before induction of TMJ inflammation $(p>0.05)$. The head withdrawal threshold was dramatically decreased $20 \mathrm{~h}$ after induction of TMJ inflammation and was partially reversed by intrahippocampal injection of capsazepine ( 10 and $30 \mathrm{nmol}, n=4)$ and 5 '-iodo-resiniferatoxin ( 0.1 and $0.5 \mathrm{nmol}, n=$ 4), but not vehicle ( $n=3$ and 5 , respectively). ${ }^{*} p<0.05$ versus vehicle group at the same time
Sakiyama et al., 1998; Wei et al., 2000). Moreover, intrahippocampal injections of lidocaine or the antagonists of $5 \mathrm{HT}_{2 \mathrm{~A} / 2 \mathrm{c}}$ and NMDA receptors decreased nociceptive behaviors (McKenna and Melzack, 1992, 2001; Soleimannejad et al., 2006, 2007). In support of this suggestion, we also provided additional data here showing that CFA-induced TMJ inflammation resulted in a significant increase of TRPV1 expression in the hippocampus but not in the amygdala, prefrontal cortex, and thalamus, indicating that the effect of TMJ inflammation on TRPV1 expression in the hippocampus was relatively specific but not caused by a general effect on TRPV1 expression in other brain regions (as shown in Fig. 5). Moreover, it appears that estradiol was not only required for TMJ inflammation-induced upregulation of hippocampal TRPV1 expression, but it also potentiated this upregulation further (Fig. 4). These results were consistent with the finding from a previous study in which estradiol induced TRPV1 expression in the dorsal root ganglion neurons (Tong et al., 2006). Although accumulating data imply that the hippocampal TRPV1 is possibly involved in pain processing (Wei et al., 2000; Lathe, 2001), there was no direct evidence to support this notion. Whether the hippocampal TRPV1 was directly involved in pain processing in the CNS still remains to be addressed.

To address this question, we generated TMJ inflammation in the rats at the proestrous stage, at which the plasma levels of estradiol are highest during the estrous cycle, and injected TRPV1 antagonists to block the function of hippocampal TRPV1 in vivo. With the confirmation of all the injection sites within the CA1 region, intrahippocampal injection of capsazepine and $5^{\prime}$-iodoresiniferatoxin significantly attenuated mechanical allodynia of the inflamed TMJ and improved food intake. Furthermore, in the estradiol-treated rats, intrahippocampal injection of the TRPV1 antagonists also showed similar effects on attenuation of allodynia of the inflamed TMJ and improvement of food intake. These results were not likely caused by neuratoxic effects of the TRPV1 antagonists, since there was no behavioral difference between the antagonist groups and the control groups before induction of TMJ inflammation. These results, for the first time, provided direct evidence to demonstrate the involvement of hippocampal TRPV1 in TMJ inflammatory pain. These results also further supported the notion that the hippocampus is involved in sex-based differences of pain (Aloisi et al., 1996, 1997; Henderson et al., 2008).

\section{Efficacy of estradiol administration}

In the present study, estradiol replacement was performed by a single injection paradigm with variable doses of estradiol designed to produce different levels of circulating estradiol. The plasma levels of estradiol were dose-dependently increased with the doses of replaced estradiol, which fulfilled our purpose of producing different levels of circulating estradiol. Comparatively, the body weight was also decreased with the increased plasma levels of estradiol, further confirming the effectiveness of

$\leftarrow$

point; $\# p<0.05$ versus vehicle group and the group injected with $10 \mathrm{nmol}$ of capsazepine at the same time point (independent-samples $t$ test). C, $\boldsymbol{D}$, Food intake was improved by intrahippocampal injection of TRPV1 antagonist capsazepine $(\boldsymbol{C})$ and 5 '-iodo-resiniferatoxin $(\boldsymbol{D})$ into the $C A 1$ region. Food intake was not different between intrahippocampal injection of capsazepine $(30 \mathrm{nmol}, n=6)$ and vehicle $(n=5)$ or $5^{\prime}$-iodo-resiniferatoxin $(0.5 \mathrm{nmol}, n=6)$ and vehicle $(n=6)$ before induction of TMJ inflammation. Intrahippocampal injection of capsazepine ( 10 and $30 \mathrm{nmol}, n=4)$ and $5^{\prime}$-iodo-resiniferatoxin ( 0.1 and $\left.0.5 \mathrm{nmol}, n=4\right)$, but not vehicle ( $n=3$ and 5 respectively), blocked the decrease of food intake caused by TMJ inflammation. ${ }^{*} p<0.05$ versus vehicle group (independent-samples $t$ test). 


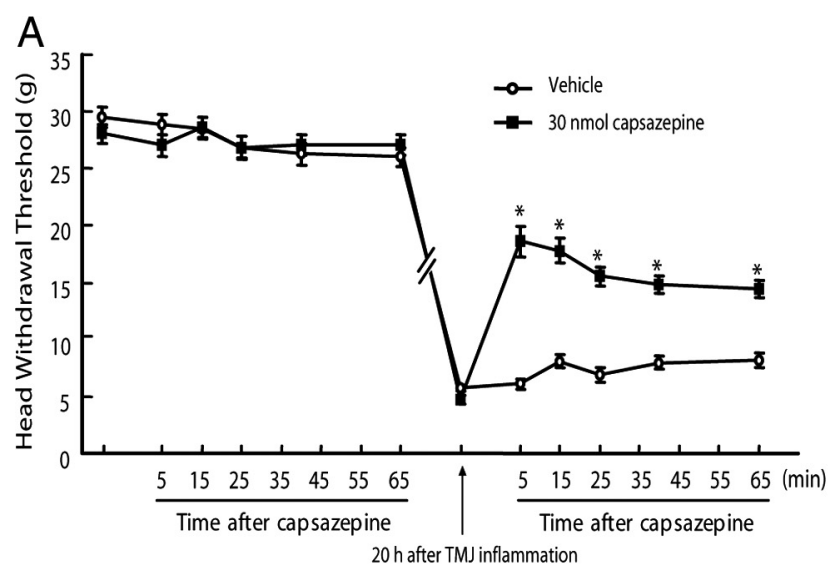

B

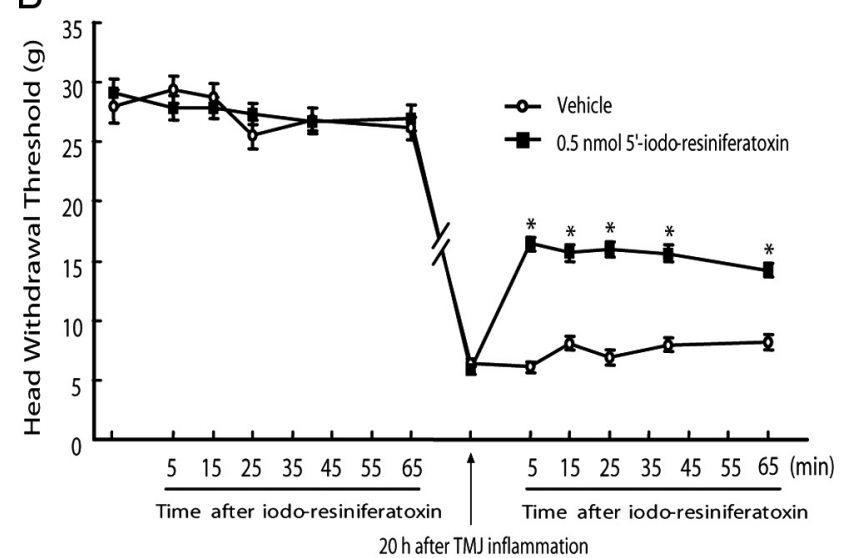

C

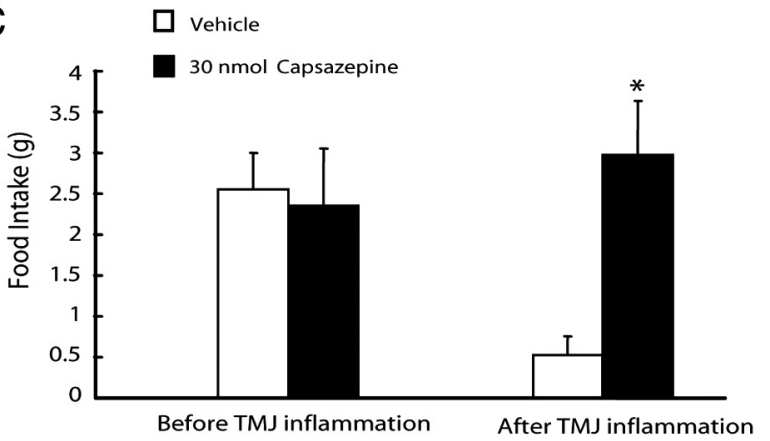

$\mathrm{D}$

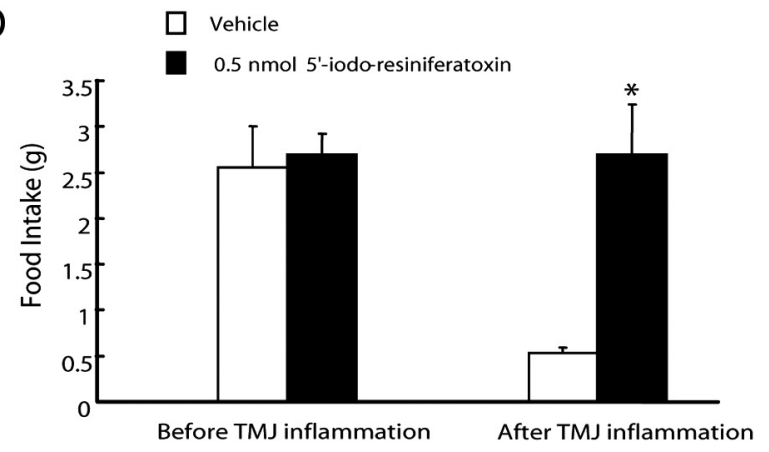

Figure 8. Attenuation of mechanical allodynia of inflamed TMJ by blocking TRPV1 in the hippocampus of estradiol (200 $\mu \mathrm{g}$ )-treated ovariectomized rats. $\boldsymbol{A}, \boldsymbol{B}$, Head withdrawal threshold was partially reversed by intrahippocampal injection of TRPV1 antagonist capsazepine ( $\boldsymbol{A})$ and $5^{\prime}$-iodo-resiniferatoxin $(\boldsymbol{B})$ into the $C A 1$ region of the hippocampus. The baseline of head withdrawal threshold was not different between intrahippocampal injection of capsazepine (30 $\mathrm{nmol}, n=6)$ and vehicle $(n=5)$ or $5^{\prime}$-iodo-resiniferatoxin $(0.5 \mathrm{nmol}, n=5)$ and vehicle $(n=$ 5) before induction of TMJ inflammation ( $p>0.05$ ). The threshold was dramatically decreased $20 \mathrm{~h}$ after induction of TMJ inflammation and was partially reversed by intrahippocampal the ovariectomy and estradiol replacement. Although the plasma levels of estradiol of rats during the estrous cycle vary in a big range in the literature, the plasma level of estradiol of the group replaced at the dose of $80 \mu \mathrm{g}$ was shown to be within the physiological range (Dupon and Kim, 1973; Lerner et al., 1990). Compared with the results of a previous study in which the plasma level of estradiol was measured in the pregnant rats, the plasma level of estradiol $(102 \pm 20.5 \mathrm{pg} / \mathrm{ml})$ of the group replaced at the dose of $200 \mu \mathrm{g}$ was also lower than that $(548 \pm 66 \mathrm{pmol} / \mathrm{L}$ or $149 \pm 17.9 \mathrm{pg} / \mathrm{ml}$ ) of the late pregnant rats (Fang et al., 1996), while still falling into the physiological range. One single injection of estradiol per day in the present study may have disadvantages, as it may cause a "surge" of the plasma level of estradiol once each day instead of once every 4-5 d in intact female rats during the estrous cycle (Wang et al., 1999). Nevertheless, this approach of estradiol administration mimicked the fluctuation of circulating estradiol of rats during the estrous cycle and allowed us to examine the effects of estradiol on TMJ pain and hippocampal TRPV1 expression in the ovariectomized rats.

\section{Food intake as an indicator for TMJ pain}

It has been suggested that food intake could be an important indicator for TMJ inflammation/pain (Harper et al., 2000; Kerins et al., 2003). Our results also showed that food intake decreased with the decreased head withdrawal threshold after induction of TMJ inflammation, further supporting that food intake can be a proper indicator for TMJ inflammation/pain. However, our result was contrary to a previous report in which the $24 \mathrm{~h}$ food intake was increased in the ovariectomized rats with estradiol replacement, compared with that in the rats ovariectomized without estradiol replacement after induction of TMJ inflammation (Guan et al., 2005). This discrepancy could be caused by a different means of meal pattern analysis. In our experiments there was a period of time for fasting to cause the rats to become hungry before the measurement of food intake and food eaten during the period of $2 \mathrm{~h}$, which was counted as food intake. Several studies have already demonstrated that food intake in $24 \mathrm{~h}$ is not changed, but the duration of the meal is extended in rats with TMJ inflammation (Harper et al., 2000; Kerins et al., 2003). Therefore, our food intake measurement in a limited time period might better reflect the severity of TMJ inflammation and pain.

In conclusion, we demonstrated here that estradiol concomitantly potentiated hippocampal TRPV1 expression and mechanical allodynia of inflamed TMJ and that the hippocampal TRPV1 was involved in mechanical allodynia of inflamed TMJ. These results suggested that estradiol could modulate TMJ pain through the TRPV1 signaling pathway in the hippocampus. These results also imply that the hippocampal TRPV1 may be a potential target for treatment of TMD pain.

$\leftarrow$

injection of capsazepine ( $30 \mathrm{nmol}, n=6)$ and 5 '-iodo-resiniferatoxin $(0.5 \mathrm{nmol}, n=5)$, but not vehicle $(n=5)$. ${ }^{*} p<0.05$ versus vehicle group at the same time point (independent-samples $t$ test). C, D, Food intake was improved by intrahippocampal injection of TRPV1 antagonist capsazepine $(\boldsymbol{C})$ and $5^{\prime}$-iodo-resiniferatoxin $(\boldsymbol{D})$ into the $(A 1$ region of estradiol-treated ovariectomized rats. Food intake was not different between intrahippocampal injection of capsazepine $(30 \mathrm{nmol}, n=6)$ and vehicle $(n=5)$ or $5^{\prime}$-iodo-resiniferatoxin $(0.5 \mathrm{nmol}, n=5)$ and vehicle $(n=5)$ before induction of TMJ inflammation. Intrahippocampal injection of capsazepine $(30 \mathrm{nmol}, n=6)$ or $5^{\prime}$-iodo-resiniferatoxin $(0.5 \mathrm{nmol}, n=5)$, but not vehicle $(n=5)$, blocked the decrease of food intake caused by TMJ inflammation. ${ }^{*} p<0.05$ versus vehicle group (independent-samples $t$ test). 


\section{References}

Abubaker AO, Raslan WF, Sotereanos GC (1993) Estrogen and progesterone receptors in temporomandibular joint discs of symptomatic and asymptomatic persons: a preliminary study. J Oral Maxillofac Surg 51:1096-1100.

Aloisi AM, Albonetti ME, Carli G (1996) Formalin-induced changes in adrenocorticotropic hormone and corticosterone plasma levels and hippocampal choline acetyltransferase activity in male and female rats. Neuroscience 74:1019-1024.

Aloisi AM, Zimmermann M, Herdegen T (1997) Sex-dependent effects of formalin and restraint on c-Fos expression in the septum and hippocampus of the rat. Neuroscience 81:951-958.

Alter BJ, Gereau RW 4th (2008) Hotheaded: TRPV1 as mediator of hippocampal synaptic plasticity. Neuron 57:629-631.

Bradshaw HB, Berkley KJ (2000) Estrous changes in responses of rat gracile nucleus neurons to stimulation of skin and pelvic viscera. J Neurosci 20:7722-7727.

Caterina MJ, Schumacher MA, Tominaga M, Rosen TA, Levine JD, Julius D (1997) The capsaicin receptor: a heat-activated ion channel in the pain pathway. Nature 389:816-824.

Cheng P, Ma X, Li S (2000) Histologic study of the temporomandibular joints after ovariectomy in rats (in Chinese). Zhonghua Kou Qiang Yi Xue Za Zhi 35:458-461.

Cicero TJ, Nock B, Meyer ER (1996) Gender-related differences in the antinociceptive properties of morphine. J Pharmacol Exp Ther 279: $767-773$.

Craft RM (2007) Modulation of pain by estrogens. Pain 132 [Suppl 1]: S3-S12.

Cristino L, de Petrocellis L, Pryce G, Baker D, Guglielmotti V, Di Marzo V (2006) Immunohistochemical localization of cannabinoid type 1 and vanilloid transient receptor potential vanilloid type 1 receptors in the mouse brain. Neuroscience 139:1405-1415.

Cui M, Honore P, Zhong C, Gauvin D, Mikusa J, Hernandez G, Chandran P, Gomtsyan A, Brown B, Bayburt EK, Marsh K, Bianchi B, McDonald H, Niforatos W, Neelands TR, Moreland RB, Decker MW, Lee CH, Sullivan JP, Faltynek CR (2006) TRPV1 receptors in the CNS play a key role in broad-spectrum analgesia of TRPV1 antagonists. J Neurosci 26: 9385-9393.

Derbyshire SW, Jones AK, Gyulai F, Clark S, Townsend D, Firestone LL (1997) Pain processing during three levels of noxious stimulation produces differential patterns of central activity. Pain 73:431-445.

Dupon C, Kim MH (1973) Peripheral plasma levels of testosterone, androstenedione, and oestradiol during the rat oestrous cycle. J Endocrinol 59:653-654.

Evrard HC, Balthazart J (2004) Rapid regulation of pain by estrogens synthesized in spinal dorsal horn neurons. J Neurosci 24:7225-7229.

Fang X, Wong S, Mitchell (1996) Relationships among sex steroids, oxytocin, and their receptors in the rat uterus during late gestation and at parturition. Endocrinology 137:3213-3219.

Gaumond I, Arsenault P, Marchand S (2005) Specificity of female and male sex hormones on excitatory and inhibitory phases of formalin-induced nociceptive responses. Brain Res 1052:105-111.

Gibson HE, Edwards JG, Page RS, Van Hook MJ, Kauer JA (2008) TRPV1 channels mediate long-term depression at synapses on hippocampal interneurons. Neuron 57:746-759.

Guan G, Kerins CC, Bellinger LL, Kramer PR (2005) Estrogenic effect on swelling and monocytic receptor expression in an arthritic temporomandibular joint model. J Steroid Biochem Mol Biol 97:241-250.

Harper RP, Kerins CA, Talwar R, Spears R, Hutchins B, Carlson DS, McIntosh JE, Bellinger LL (2000) Meal pattern analysis in response to temporomandibular joint inflammation in the rat. J Dent Res 79:1704-1711.

Henderson LA, Gandevia SC, Macefield VG (2008) Gender differences in brain activity evoked by muscle and cutaneous pain: A retrospective study of single-trial fMRI data. Neuroimage 39:1867-1876.

Hertrampf T, Gruca MJ, Seibel J, Laudenbach U, Fritzemeier KH, Diel P (2007) The bone-protective effect of the phytoestrogen genistein is mediated via ER alpha-dependent mechanisms and strongly enhanced by physical activity. Bone 40:1529-1535.

Holmlund A, Hellsing G, Axelsson S (1989) The temporomandibular joint: a comparison of clinical and arthroscopic findings. J Prosthet Dent 62:61-65.

Ishii H, Tsurugizawa T, Ogiue-Ikeda M, Asashima M, Mukai H, Murakami G, Hojo Y, Kimoto T, Kawato S (2007) Local production of sex hormones and their modulation of hippocampal synaptic plasticity. Neuroscientist 13:323-334.

Israel HA, Diamond BE, Saed-Nejad F, Ratcliffe A (1997) Correlation between arthroscopic diagnosis of osteoarthritis and synovitis of the human temporomandibular joint and keratan sulfate levels in the synovial fluid. J Oral Maxillofac Surg 55:210-217, discussion 217-218.

Kerins CA, Carlson DS, McIntosh JE, Bellinger LL (2003) Meal pattern changes associated with temporomandibular joint inflammation/pain in rats; analgesic effects. Pharmacol Biochem Behav 75:181-189.

Kopp S (1998) The influence of neuropeptides, serotonin, and interleukin 1beta on temporomandibular joint pain and inflammation. J Oral Maxillofac Surg 56:189-191.

Kuba T, Wu HB, Nazarian A, Festa ED, Barr GA, Jenab S, Inturrisi CE, Quinones-Jenab V (2006) Estradiol and progesterone differentially regulate formalin-induced nociception in ovariectomized female rats. Horm Behav 49:441-449.

Landi N, Manfredini D, Lombardi I, Casarosa E, Bosco M (2004) 17-betaestradiol and progesterone serum levels in temporomandibular disorder patients. Minerva Stomatol 53:651-660.

Lathe R (2001) Hormones and the hippocampus. J Endocrinol 169: 205-231.

LeResche L, Saunders K, Von Korff MR, Barlow W, Dworkin SF (1997) Use of exogenous hormones and risk of temporomandibular disorder pain. Pain 69:153-160.

LeResche L, Mancl L, Sherman JJ, Gandara B, Dworkin SF (2003) Changes in temporomandibular pain and other symptoms across the menstrual cycle. Pain 106:253-261.

Lerner SP, Meredith S, Thayne WV, Butcher RL (1990) Age-related alterations in follicular development and hormonal profiles in rats with 4-day estrous cycles. Biol Reprod 42:633-638.

Li HB, Mao RR, Zhang JC, Yang Y, Cao J, Xu L (2008) Antistress effect of TRPV1 channel on synaptic plasticity and spatial memory. Biol Psychiatry 64:286-292.

Liu F, Day M, Muniz LC, Bitran D, Arias R, Revilla-Sanchez R, Grauer S, Zhang G, Kelley C, Pulito V, Sung A, Mervis RF, Navarra R, Hirst WD, Reinhart PH, Marquis KL, Moss SJ, Pangalos MN, Brandon NJ (2008) Activation of estrogen receptor-beta regulates hippocampal synaptic plasticity and improves memory. Nat Neurosci 11:334-343.

Loyd DR, Wang X, Murphy AZ (2008) Sex differences in $\mu$-opioid receptor expression in the rat midbrain periaqueductal gray are essential for eliciting sex differences in morphine analgesia. J Neurosci 28:14007-14017.

Mannino CA, South SM, Inturrisi CE, Quinones-Jenab V (2005) Pharmacokinetics and effects of 17beta-estradiol and progesterone implants in ovariectomized rats. J Pain 6:809-816.

Mannino CA, South SM, Quinones-Jenab V, Inturrisi CE (2007) Estradiol replacement in ovariectomized rats is antihyperalgesic in the formalin test. J Pain 8:334-342.

Marsch R, Foeller E, Rammes G, Bunck M, Kossl M, Holsboer F, Zieglgansberger W, Landgraf R, Lutz B, Wotjak CT (2007) Reduced anxiety, conditioned fear, and hippocampal long-term potentiation in transient receptor potential vanilloid type 1 receptor-deficient mice. J Neurosci 27:832-839.

McGaraughty S, Chu KL, Bitner RS, Martino B, El Kouhen R, Han P, Nikkel AL, Burgard EC, Faltynek CR, Jarvis MF (2003) Capsaicin infused into the PAG affects rat tail flick responses to noxious heat and alters neuronal firing in the RVM. J Neurophysiol 90:2702-2710.

McKenna JE, Melzack R (1992) Analgesia produced by liocaine microinjection into the dentate gyrus. Pain 49:105-112.

McKenna JE, Melzack R (2001) Blocking NMDA receptors in the hippocampal dentate gyrus with AP5 produces analgesia in the formalin pain test. Exp Neurol 172:92-99.

Mezey E, Toth ZE, Cortright DN, Arzubi MK, Krause JE, Elde R, Guo A, Blumberg PM, Szallasi A (2000) Distribution of mRNA for vanilloid receptor subtype 1 (VR1), and VR1-like immunoreactivity, in the central nervous system of the rat and human. Proc Natl Acad Sci U S A 97: 3655-3660.

Murakami K, Segami N, Fujimura K, lizuka T (1991) Correlation between pain and synovitis in patients with internal derangement of the temporomandibular joint. J Oral Maxillofac Surg 49:1159-1161, discussion 1162.

Okuda T, Yasuoka T, Nakashima M, Oka N (1996) The effect of ovariectomy on the temporomandibular joints of growing rats. J Oral Maxillofac Surg 54:1201-1210, discussion 1210-1211. 
Paxinos G, Watson C (1997) The rat brain in stereotaxic coordinates. New York: Academic.

Ren K (1999) An improved method for assessing mechanical allodynia in the rat. Physiol Behav 67:711-716.

Ryan SM, Maier SF (1988) The estrous cycle and estrogen modulate stressinduced analgesia. Behav Neurosci 102:371-380.

Sakiyama Y, Sato A, Senda M, Ishiwata K, Toyama H, Schmidt RF (1998) Positron emission tomography reveals changes in global and regional cerebral blood flow during noxious stimulation of normal and inflamed elbow joints in anesthetized cats. Exp Brain Res 118:439-446.

Soleimannejad E, Semnanian S, Fathollahi Y, Naghdi N (2006) Microinjection of ritaserin into the dorsal hippocampal CAl and dentate gyrus decrease nociceptive behavior in adult male rat. Behav Brain Res 168: 221-225.

Soleimannejad E, Naghdi N, Semnanian S, Fathollahi Y, Kazemnejad A (2007) Antinociceptive effect of intra-hippocampal CAl and dentate gyrus injection of MK801 and AP5 in the formalin test in adult male rats. Eur J Pharmacol 562:39-46.

Starowicz K, Maione S, Cristino L, Palazzo E, Marabese I, Rossi F, de Novellis V, Di Marzo V (2007) Tonic endovanilloid facilitation of glutamate release in brainstem descending antinociceptive pathways. J Neurosci 27:13739-13749.

Szallasi A, Cortright DN, Blum CA, Eid SR (2007) The vanilloid receptor TRPV1: 10 years from channel cloning to antagonist proof-of-concept. Nat Rev Drug Discov 6:357-372.
Terzian AL, Aguiar DC, Guimaraes FS, Moreira FA (2009) Modulation of anxiety-like behaviour by transient receptor potential vanilloid type 1 (TRPV1) channels located in the dorsolateral periaqueductal gray. Eur Neuropsychopharmacol 19:188-195.

Tian YF, Zhang PB, Xiao XL, Zhang JS, Zhao JJ, Kang QY, Chen XL, Qiu F, Liu Y (2007) The quantification of ADAMTS expression in an animal model of cerebral ischemia using real-time PCR. Acta Anaesthesiol Scand 51:158-164.

Tong C, Conklin D, Clyne BB, Stanislaus JD, Eisenach JC (2006) Uterine cervical afferents in thoracolumbar dorsal root ganglia express transient receptor potential vanilloid type 1 channel and calcitonin gene-related peptide, but not $\mathrm{P} 2 \mathrm{X} 3$ receptor and somatostatin. Anesthesiology 104:651-657.

Toth A, Boczan J, Kedei N, Lizanecz E, Bagi Z, Papp Z, Edes I, Csiba L, Blumberg PM (2005) Expression and distribution of vanilloid receptor 1 (TRPV1) in the adult rat brain. Brain Res Mol Brain Res 135:162-168.

Wang Q, Santizo R, Baughman VL, Pelligrino DA, Iadecola C (1999) Estrogen provides neuroprotection in transient forebrain ischemia through perfusion-independent mechanisms in rats. Stroke 30:630-637.

Warren MP, Fried JL (2001) Temporomandibular disorders and hormones in women. Cells Tissues Organs 169:187-192.

Wei F, Xu ZC, Qu Z, Milbrandt J, Zhuo M (2000) Role of EGR1 in hippocampal synaptic enhancement induced by tetanic stimulation and amputation. J Cell Biol 149:1325-1334. 